\title{
The correlation between the enzymatic saccharification and the multidimensional structure of cellulose changed by different pretreatments
}

Ting Cui ${ }^{1,2}$, Jihong $\mathrm{Li}^{1,2^{*}}$, Zhipei Yan ${ }^{1,2}$, Menghui $\mathrm{Yu}^{1,2}$ and Shizhong $\mathrm{Li}^{1,2^{*}}$

\begin{abstract}
Background: The bioconversion of cellulose into simple sugars or chemicals has attracted extensive attention in recent decades. The crystal allomorphs of cellulose are key factor affecting cellulose saccharification. However, due to the influence of lignin, hemicelluloses, and different characterization methods in the literature, the effect of cellulose allomorphs on cellulose saccharification is still unresolved. Thus, a systematic research on the effect of different cellulose allomorphs on enzymatic saccharification was required.

Results: Multiple approaches, including the use of ionic liquid (IL), ethylenediamine (EDA), glycerol, and sodium hydroxide, were used to pretreat a-cellulose in this work. The properties of the obtained cellulose (crystallinity, lattice spacing, specific surface area, and wettability) were characterized by X-ray diffraction, Brunauer, Emmett, and Teller (BET) specific surface area analysis, and water contact angle analysis, respectively. The distance of the lattice spacing of cellulose III was longer than that of other cellulose samples. The crystallinity and water contact angles of the cellulose samples were ranked in the following order: cellulose treated with $\mathrm{IL}<$ cellulose treated with $\mathrm{NaOH}<$ cellulose treated with EDA < cellulose without treatment $<$ cellulose treated with glycerol. Cellulose treated with IL, with a crystallinity index value of $20 \%$, was very close to amorphous cellulose. After $72 \mathrm{~h}$ hydrolysis, the cellulose conversion ratio ranged from $43 \%$ to $99 \%$. Cellulose treated with IL exhibited the best hydrolysis profile, followed by cellulose treated with EDA.

Conclusion: Ionic liquid pretreatment significantly altered the ultrastructure and morphology of cellulose samples, making cellulose much easier for enzymes to digest due to its significantly high amorphous content. However, when the impact of amorphous content was not considered, the allomorph easiest for enzymes to digest was cellulose III, followed by cellulose $I I$, cellulose $I_{\alpha}$ and cellulose $I_{\beta}$. When the cellulose crystallinity index was similar, the allomorph type was the dominant factor. The amorphous content had a strong positive influence on cellulose digestibility. Water contact angle was also an important factor in evaluating the enzymatic hydrolysis efficiency of cellulose except for cellulose III. A high wettability of cellulose enhanced the enzymatic hydrolysis when the crystal allomorph of all the cellulosic samples was the same.
\end{abstract}

Keywords: Crystalline cellulose, Allomorph, Crystallinity, Water contact angle, Lattice spacing, Specific surface area

\footnotetext{
*Correspondence: nklijh@126.com; szli@mail.tsinghua.edu.cn

${ }^{1}$ Institute of Nuclear and New Energy Technology, Tsinghua University, Beijing 100084, China

${ }^{2}$ Beijing Engineering Research Centre of Biofuels, Tsinghua University,

Beijing 100084, China
}

\section{Biomed Central}

(c) 2014 Cui et al.; licensee BioMed Central Ltd. This is an Open Access article distributed under the terms of the Creative Commons Attribution License (http://creativecommons.org/licenses/by/4.0), which permits unrestricted use, distribution, and reproduction in any medium, provided the original work is properly credited. The Creative Commons Public Domain Dedication waiver (http://creativecommons.org/publicdomain/zero/1.0/) applies to the data made available in this article, unless otherwise stated. 


\section{Background}

Cellulose, the main component of lignocellulose, is the most abundant natural carbohydrate resource on the earth [1]. The bioconversion of cellulose into simple sugars or chemicals has attracted extensive attention for the sustainable development of the human society in recent decades. Cellulose is generally cross-linked with hemicellulose and lignin in the plant cell wall [2]. Hence, it is necessary to disrupt the structure of the original cell wall during the process of cellulose bioconversion. For this reason, most research for bioconversion of lignocellulosic feedstock into simple sugars has focused on increasing the enzyme accessibility of cellulose by the removal of hemicellulose or lignin [3-7]. In order for cellulose to be more conducive to enzymatic saccharification, various pretreatment approaches for cellulosic resources have been developed, such as ball-milling, the use of dilute acid, alkaline treatment, ammonia explosion, and so on $[1,3,5,8,9]$. However, due to the complex structure of the cell wall, multiple factors (for example, delignification, hemicellulose solubilization, porosity, enzyme accessibility, and cellulose crystallinity) interact with each other, and thus the results drawn from different works in the literature have led to confusing conclusions about the recalcitrance of lignocellulosic feedstock.

Besides the effect of lignin and hemicellulose on cellulose bioconversion, the recalcitrant nature of crystalline cellulose, such as multiple hydrogen bonding and a high degree of crystallinity and hydrophobicity, also contribute to the low saccharification efficiency seen in samples of pure cellulose, Avicel, and cotton fibers [10-12]. Previous research revealed that the modification of the cellulose crystal structure by pretreatments tended to affect the enzymatic hydrolysis of cellulose [13-16]. Chundawat and his co-workers reported that the hydrolysis yield of Avicel increased 1.5- and 2-fold after it was treated with $\mathrm{NaOH}$ and $\mathrm{NH}_{3}$, respectively [12]. Ciolacu et al. also reported that the enzyme saccharification yield of Avicel $\mathrm{PH}-101$ increased from $10 \%$ to $62 \%$ after it was treated with $17.5 \% \mathrm{NaOH}$ for $24 \mathrm{~h}$ at $15^{\circ} \mathrm{C}$, and from $10 \%$ to $18 \%$ after the samples were soaked in organic amine (100\% ethylenediamine, EDA) for $24 \mathrm{~h}$ at room temperature [17]. In these works, the particle size of the cellulose samples was changed, and more importantly, the allomorphic form of cellulose was modified. These results indicated that the allomorphic form of cellulose could be a key factor in the improvement of the saccharification of cellulose. Moreover, changing the allomorph of cellulose might be a better alternative and more feasible method to enhance the rate of subsequent enzymatic catalysis, as compared to trying to discover novel microorganisms for the bioconversion process.

The allomorph of native cellulose is cellulose I, including cellulose $I_{\alpha}$ and $I_{\beta}[18]$. After pretreatment, cellulose crystallizes into various allomorphs (cellulose I, II, III, and IV) with different packing arrangements [1,19]. Cellulose II is formed when native cellulose regenerates from a dissolved state or is mercerized with alkali. Cellulose I or cellulose II treated with liquid ammonia or certain amines would lead to the formation of cellulose III [1]. Cellulose IV is a disordered form of cellulose $I_{\beta}$ [19].

Most research conducted on the enzymatic digestibility of cellulose allomorphs only focuses on one form and the related pretreatment $[13,20,21]$. However, because of the different characterization methods of cellulose properties and hydrolysis conditions utilized in these studies, the data cannot be easily compared to determine the optimal cellulose allomorph for enzymatic bioconversion. We still lack an understanding of the relationship between various cellulose allomorphs and cellulose enzymatic saccharification and of which factors are the most influential in the hydrolysis process.

The main objective of this study was to attain a systematic understanding of the effect of different cellulose allomorphs produced by the various pretreatments on enzymatic saccharification. In this study, we used multiple approaches, including the use of ionic liquid (IL), EDA, glycerol, and sodium hydroxide, to pretreat $\alpha$ cellulose. The physical and chemical properties (crystallinity index, lattice spacing, specific surface area, and wettability) of the cellulose obtained were characterized by X-ray diffraction (XRD), BET specific surface area analysis, and water contact angle analysis, respectively. The correlation of crystalline cellulose structure and enzymatic hydrolysis was discussed.

\section{Materials and methods}

\section{Materials}

The cellulose samples were prepared as pictured in Figure 1.

Cellulose $\mathrm{I}_{\alpha}$ (untreated cellulose, UN-C): $\alpha$-cellulose (sigma) was used without further purification.

Cellulose $\mathrm{I}_{\beta}$ (glycerol treated cellulose, GT-C): $0.5 \mathrm{~g} \alpha-$ cellulose specimens were inserted in a small glass ampule filled with $5 \mathrm{~mL}$ glycerol under nitrogen. The ampule was sealed and heated at $270^{\circ} \mathrm{C}$ for $1 \mathrm{~h}$. The ampule was then cooled naturally and washed thoroughly with distilled water until it reached neutrality, then lyophilized.

Cellulose II: cellulose II was obtained by two methods.

ST-C (sodium hydroxide treated cellulose): $\alpha$-cellulose powders were soaked in $16.5 \% \mathrm{NaOH}$ for $2 \mathrm{~h}$, at $25^{\circ} \mathrm{C}$, followed by washing thoroughly with distilled water until neutrality and lyophilization.

IT-C (IL treated cellulose): for the cellulose II samples prepared by IL, $\alpha$-cellulose was immersed in 1-butyl-3methylimidazolium chloride ([BMIM]Cl) at $90^{\circ} \mathrm{C}$ for $3 \mathrm{~h}$, followed by washing thoroughly with distilled water and lyophilization. 


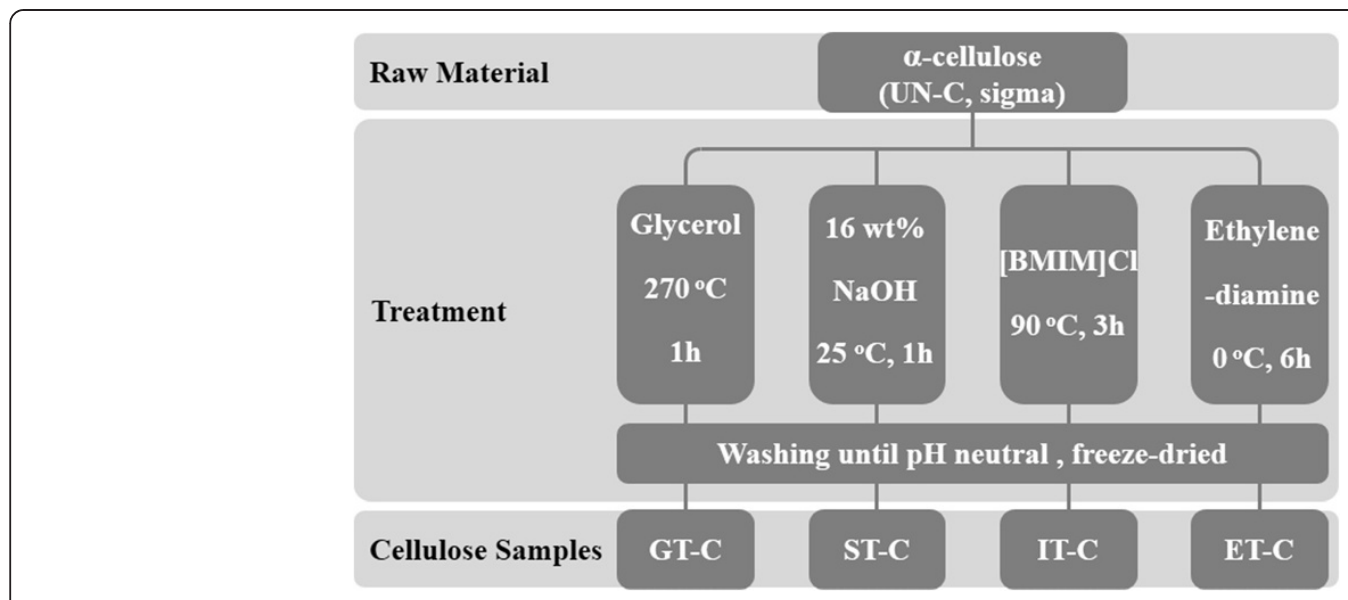

Figure 1 Different types of crystalline cellulose preparation.

Cellulose III (ET-C, EDA treated cellulose): cellulose III was prepared by soaking $\alpha$-cellulose in EDA for $6 \mathrm{~h}$ in an ice-water bath. Then the cellulose-amine complex was washed with anhydrous ethanol until it reached neutrality and then lyophilized.

\section{Methods}

\section{Water contact angle}

The water contact angles of cellulose substrate were determined using the Kruss Tensiometer K100 (Kruss $\mathrm{GmbH}$, Hamburg, Germany) to determine the tensiometry. The experimental procedures were performed according to the literature [10].

\section{$X$-ray diffraction}

The lyophilized samples were scanned on a Bruker D8 Advance diffractometer (Bruker, Germany) using $\mathrm{Cu} / \mathrm{K \alpha}$ radiation $(1.54 \AA)$ generated at $45 \mathrm{kV}$ and $40 \mathrm{~mA}$, at room temperature. The scan speed was $0.02^{\circ} \mathrm{s}^{-1}$ with a step size of $0.02^{\circ}$, and the scans were collected from $2 \theta=5$ to $40^{\circ}$. The crystallinity index ( $\left.\mathrm{CrI}\right)$ was calculated using the peak intensity method [22]:

$$
\mathrm{CrI}=\frac{\left(\mathrm{I}_{020}-\mathrm{I}_{\mathrm{am}}\right)}{\mathrm{I}_{\mathrm{am}}} * 100 \%,
$$

where $\mathrm{I}_{020}$ is the intensity at the main peak of the cellulose samples, which usually lies around $22.5^{\circ}, 21.9^{\circ}$, and $21^{\circ}$ for cellulose I, cellulose II, and cellulose III, respectively. $\mathrm{I}_{\mathrm{am}}$ is the intensity of amorphous cellulose content at $2 \theta=18^{\circ}$.

The lattice spacing (d-spacing) was calculated using Bragg's equation [17]:

$$
\lambda=2 \mathrm{~d}_{\mathrm{hll}} \cdot \sin \theta,
$$

where $d_{\text {hkl }}$ is the lattice spacing of the crystallographic planes, $\theta$ is the corresponding Bragg angle, and $\lambda$ is the $\mathrm{X}$-ray wavelength $(0.154 \mathrm{~nm})$.
Fourier transform infrared spectroscopy (FTIR) microscopy

Samples were prepared by mixing $2 \mathrm{mg}$ cellulose with $200 \mathrm{mg}$ of spectroscopic grade $\mathrm{KBr}$. The FTIR spectra were recorded using a Nicolet 6700 spectrometer with detector at $0.4 \mathrm{~cm}^{-1}$ resolution and 64 scans. To determine the $I_{\alpha}$ fraction in the cellulose samples, the characteristic IR absorption bands at $750 \mathrm{~cm}^{-1}$ for $I_{\alpha}$ and $710 \mathrm{~cm}^{-1}$ for $I_{\beta}$ were used to determine the cellulose crystal form, as outlined in a previous report [23]. The IR index for the fraction $\left(f_{I \alpha}\right)$ was calculated, using the band areas for $I_{\alpha}\left(A_{750}\right)$ and $I_{\beta}\left(A_{710}\right)$ :

$$
f_{I \alpha}=\mathrm{A}_{750} /\left(\mathrm{A}_{750}+\mathrm{A}_{710}\right)
$$

\section{Scanning electron microscopy (SEM)}

The morphology of the cellulose samples was analyzed by using a Zeiss Merlin electron microscope (Carl Zeiss Microscopy, Jena, Germany) with a field emission tungsten filament electron gun, operating at $1 \mathrm{kV}$. Prior to the SEM experiment, the cellulose samples were coated with a 20 to $30 \mathrm{~nm} \mathrm{C}$ thin film to avoid the charging effect during the testing.

\section{Enzymatic hydrolysis}

Enzymatic hydrolysis of all cellulose samples was carried out in triplicate, using a rotary shaker at $50^{\circ} \mathrm{C}$ and $150 \mathrm{rpm}$ by Novozymes CTec 3 at $5 \%$ solids (w/v). $0.3 \%$ $(\mathrm{w} / \mathrm{v})$ sodium azide was added to inhibit the growth of microorganisms, while $0.05 \mathrm{M}$ sodium acetate buffer was used to maintain the $\mathrm{pH}$ at 4.8 . To determine the conversion ratio of cellulose during the enzymatic hydrolysis, the mixture was centrifuged for $5 \mathrm{~min}$ at $12,000 \mathrm{rpm}$ to terminate the reaction after $2,4,12,24$, 48 , and $72 \mathrm{~h}$. The carbohydrate concentration was analyzed by an HPLC instrument (Shimadzu, Kyoto, Japan). 
The cellulose conversion ratio was calculated according to the follow formula:

$$
\begin{aligned}
\text { Cellulose conversion ratio }= & 0.9 \times \text { glucose concentration } \\
& \times \text { hydrolysate volume } / \text { the } \\
& \text { weightof cellulose substrate } \\
& \times 100 \%
\end{aligned}
$$

\section{BET specific surface area}

Cellulose samples were oven-dried at $80^{\circ} \mathrm{C}$ for $10 \mathrm{~h}$ to minimize structural changes prior to BET analysis with $\mathrm{N}_{2}$. The BET specific surface area and pore volume distribution were determined by a Micromeritics Tristar 3020 II analyzer (Micromeritics Instrument Corporation, Norcross, GA, USA) at a relative pressure approximating unity [24].

\section{Results}

\section{Cellulose allomorphs and crystallinity}

XRD patterns of all the cellulose samples are shown in Figure 2. The results were consistent with the data reported by previous research focusing on the allomorphs of celluloses $[12,15,17,20]$. The cellulose samples treated with glycerol presented characteristic $2 \theta$ diffraction planes at $15^{\circ}(1 \overline{\mathrm{I}} 0), 16^{\circ}(110)$, and $23^{\circ}(020)$, which are still those of cellulose I. However, the allomorphic change to $I_{\beta}$ from $I_{\alpha}$ is difficult to determine with diffraction patterns. To further examine the crystalline structure of GT-C, the FTIR spectra of GT-C were recorded. As expected, the content of allomorph $\mathrm{I}_{\beta}$ in the GT-C samples exceeded 55\%, demonstrating a partial change to allomorph $\mathrm{I}_{\beta}$ (Table 1). After $\mathrm{NaOH}$ or [BMIM] $\mathrm{Cl}$ treatment, $\alpha$-cellulose converted to cellulose II with a doublet appearing at $2 \theta$ values (about $20^{\circ}$ and $22^{\circ}$ ) for the $1 \bar{I} 0$ and 020 peak. $\alpha$-cellulose converted to cellulose III

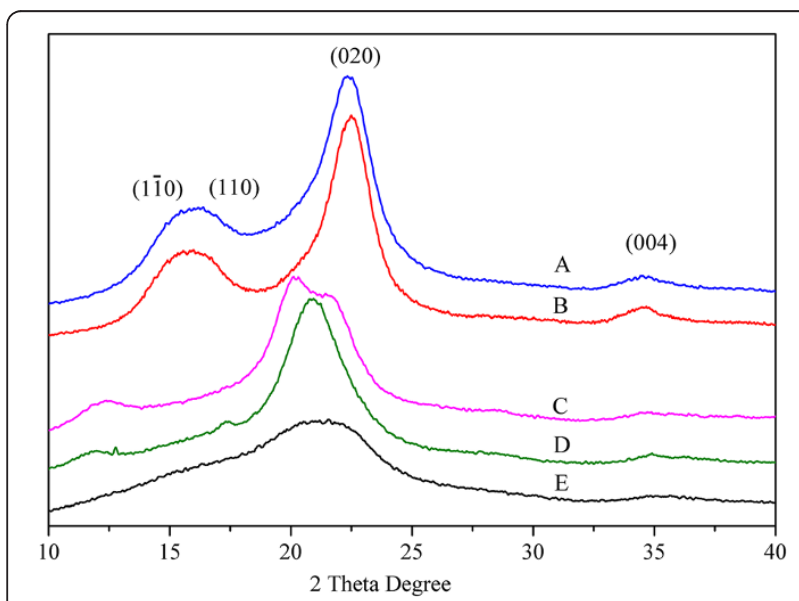

Figure 2 X-ray diffraction patterns of cellulose samples: (A) UN-C; (B) GT-C; (C) ST-C; (D) ET-C; (E) IT-C.
Table 1 The $I_{\alpha}$ fraction in GT-C samples

\begin{tabular}{lll}
\hline Cellulose sample & Cellulose $I_{\boldsymbol{\alpha}}$ fraction (\%) & Cellulose $I_{\boldsymbol{\beta}}$ fraction (\%) \\
\hline UN-C & 83 & 17 \\
GT-C & 42 & 58 \\
\hline
\end{tabular}

during the EDA treatment, with the position of the 020 peak shifting from a $2 \theta$ value of $23^{\circ}$ to $21^{\circ}$ [6].

The CrI of $\alpha$-cellulose without any further treatment was $61 \%$. The ET-C and ST-C samples exhibited a CrI of $55 \%$ and $46 \%$, respectively. After pretreatment, the IT-C samples had a CrI value of $20 \%$, a substantial reduction in the CrI value which is very close to that of amorphous cellulose. In addition, GT-C had the lowest amorphous content, with a $69 \% \mathrm{CrI}$ value.

\section{Cellulose wettability}

The cellulose wettability was characterized by measuring the cellulose water contact angle using the Kruss K100. The water contact angles of the cellulose samples were ranked in the following order: IT-C $<\mathrm{ST}-\mathrm{C}<\mathrm{ET}-\mathrm{C}<$ $\mathrm{UN}-\mathrm{C}<\mathrm{GT}-\mathrm{C}$. The water contact angle values for ET-C and $\mathrm{UN}-\mathrm{C}$ were $58.4^{\circ}$ and $60.7^{\circ}$ respectively, indicating no significant wettability difference among substrates with EDA treatment. $\mathrm{NaOH}$ treatment produced a slight increase in wettability among cellulose samples measured at a water contact angle value of $47.9^{\circ}$. Compared to the above two treatments, cellulose II prepared by IL pretreatment tended to exhibit a greater capacity of water absorption, with a $29.5^{\circ}$ water contact angle value. Cellulose treated by glycerol seemed to be the most hydrophobic compared to other samples, with a water contact angle of $66.0^{\circ}$. It was also unique in that it surpassed the value of untreated $\alpha$-cellulose. These results suggested that glycerol treatment caused the cellulose samples to be more hydrophobic, while the other three treatments changed the cellulose to be more hydrophilic. The greatest wettability cellulose samples were obtained through IL treatment.

\section{Cellulose BET specific surface area (SSA)}

The SSA values of cellulose samples were measured using the BET specific surface area method. Both the BET $\mathrm{N}_{2}$ absorption of UN-C and GT-C were near zero, and the data was too small to be detected by this method. The BET $\mathrm{N}_{2}$ SSA of IT-C $\left(8.47 \mathrm{~m}^{2} / \mathrm{g}\right)$ significantly exceeded the corresponding values of the other samples. The BET $\mathrm{N}_{2}$ SSA of ET-C $\left(0.08 \mathrm{~m}^{2} / \mathrm{g}\right)$ was larger than that of ST-C $\left(0.06 \mathrm{~m}^{2} / \mathrm{g}\right)$. As shown in Figure 3, the untreated cellulose samples were intact and had a relatively smooth surface. After glycerol treatment, the surface of the cellulose samples did not show obvious changes, although the average fiber length shortened. With $\mathrm{NaOH}$ and EDA pretreatment, the surface of the 

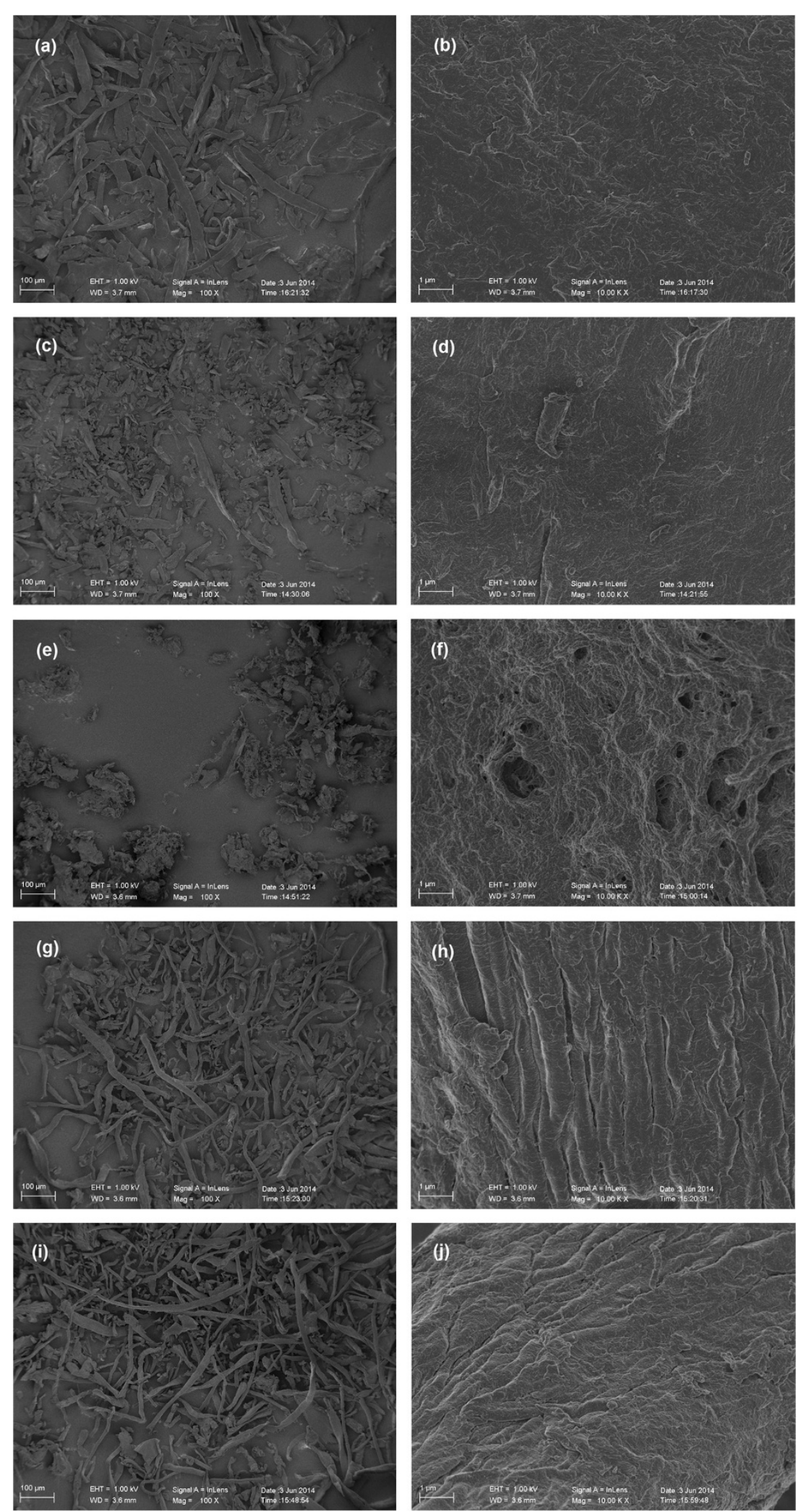

Figure 3 SEM images of different cellulose samples, UN-C (a, b), GT-C (c, d), IT-C (e, f), ST-C (g, h), and ET-C (i, j). 
cellulose samples appeared to be uneven and rough, but still maintained the fiber morphology. After regeneration from IL, the morphology of the cellulose samples was significantly changed. The surface of the IL treated cellulose had a large number of holes and the elongated structure of the fibers had disappeared.

\section{Enzymatic hydrolysis of different allomorph celluloses}

Samples of different cellulose allomorphs were hydrolyzed for $72 \mathrm{~h}$, and the cellulose conversion ratios ranged from $43 \%$ to $99 \%$ (Figure 4 ). IT-C exhibited a notably efficient hydrolysis profile; more than $70 \%$ of the substrate was converted into glucose during the first $2 \mathrm{~h}$ and the saccharification ratio reached $99 \%$ at $72 \mathrm{~h}$. ST-C and ET-C had similar enzymatic rates and the final saccharification ratio at $72 \mathrm{~h}$ was about $75 \%$. However, as shown in Figure 4, after being treated by glycerol, the cellulose samples had a much lower glucose yield, which was $30 \%$ lower than that of UN-C.

\section{Discussion}

Although the mechanism of cellulose hydrolysis has been studied intensively over the last few decades, it is still unclear because of the complex process of cellulose enzymatic hydrolysis. Most studies have been more concerned with the characterization of the cellulolytic microorganisms, and the biochemical properties of the enzymes produced by them $[25,26]$. Enhancing the enzymatic hydrolysis rate of lignocellulose substrate and altering the crystalline cellulose features, especially the cellulose allomorphs, is often ignored, because a change of cellulose crystal form does not take place for every treatment. Moreover, changing the cellulose allomorph results in changes to other features of cellulosic substrates, such as the crystallinity index and specific surface area



Figure 4 Enzymatic hydrolysis of cellulose samples. (The error bars indicate the reproducibility of digestions conducted in triplicate on the cellulose samples).
[27]. Thus, a valuable evaluation system to identify the enzymatic digestibility of cellulosic substrates is needed and essential to make the best choice for a pretreatment method.

In this paper, in order to investigate the effects of various cellulose allomorphs on enzyme hydrolysis, several pretreatment methods were utilized to change the crystal form of cellulose to obtain different cellulose allomorph samples. These pretreatments were $\mathrm{NaOH}$ mercerization, EDA soaking, glycerol treatment, and IL treatment [1,12,13,15,28-31]. The crystal allomorph of each sample was characterized by XRD or FTIR. GT-C obtained from glycerol treatment was a crystal mixture of $58 \% \mathrm{I}_{\beta}$ and $42 \% \mathrm{I}_{\alpha}$. ST-C and IT-C were allomorph II obtained from $\mathrm{NaOH}$ and IL treatment, respectively. ET-C obtained from EDA treatment was cellulose III. Unfortunately, cellulose samples with similar crystallinity index values were not obtained, although we adjusted the pretreatment conditions repeatedly. Furthermore, according to the XRD results, after pretreatments, the CrI of all the cellulose samples decreased except for the sample treated with glycerol. This result indicated that the CrI of cellulose was more sensitive to the pretreatments than the crystal form. In addition, after cellulose dissolved in [BMIM]Cl, most of the crystalline cellulose transformed into an amorphous structure. Among these four pretreatments, the cellulose sample with the lowest CrI was produced during the regeneration process from the dissolved state in IL, most likely because the strong hydrogen bonding network of crystalline cellulose was destroyed by the ionic liquid.

The CrI of cellulose is a key predictor of the enzymatic hydrolysis rate [11]. The correlation between the CrI of the five samples and cellulose conversion ratio is shown in Figure 5a. As expected, there was a negative correlation between the cellulose conversion ratio and crystallinity, whereas the ET-C sample obtained from the EDA soaking pretreatment had a significant positive deviation. According to the XRD analysis, the allomorph of ET-C was cellulose III. Comparing the CrI of ST-C with IT-C, for the same allomorph, cellulose samples with lower $\mathrm{CrI}$ had a much faster saccharification rate. Samples of UN-C and GT-C with a similar crystal allomorph also demonstrated this result. It can be concluded that amorphous content had a strong positive influence on cellulose digestibility. In a previous work, Bertran and Dale reported that most aqueous reagents could only penetrate the amorphous portion of cellulose [32]. Crystallinity and cellulose accessibility were closely related. Additionally, Hall and co-workers reported that, at low degrees of crystallinity, adsorbed enzymes were more active at the same concentration, because a more open cellulose structure would likely prevent enzyme molecules residing on neighboring chains from hindering one another [11]. Cellulose accessibility and cellulase activities 
(a)



(b)

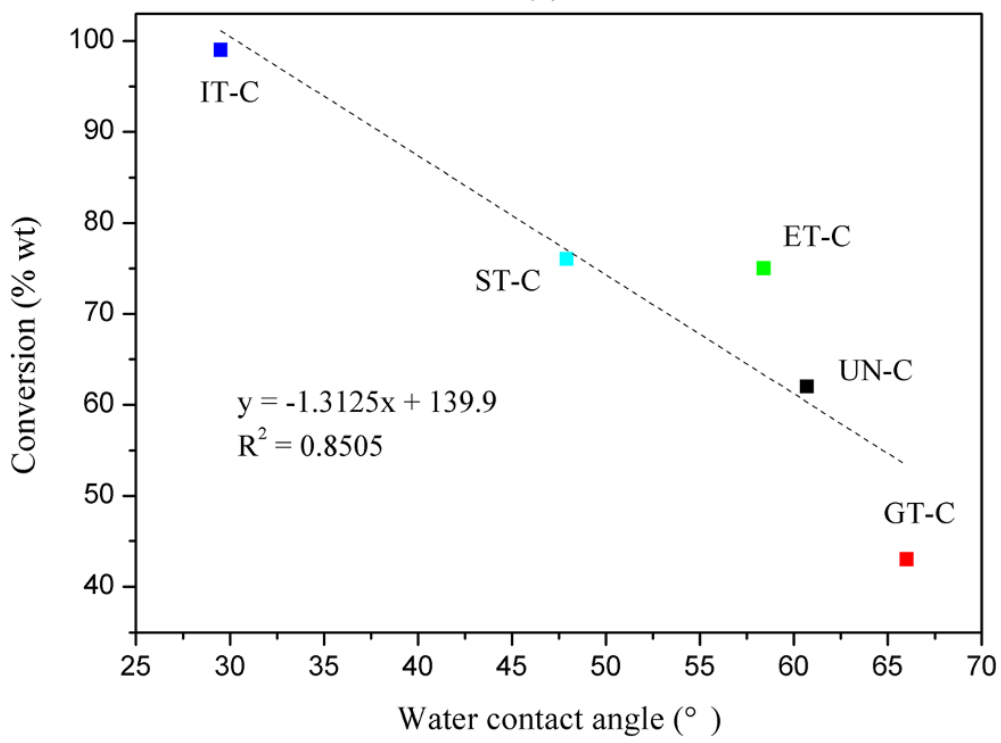

Figure 5 The correlation between crystallinity index (a), water contact angle (b), and cellulose conversion.

were both suggested to be important factors affecting enzymatic hydrolysis rates. Therefore, amorphous content contributed to increased cellulose digestibility.

However, in the case of ET-C, this conclusion did not seem to apply, because its $\mathrm{CrI}$ was obviously higher than that of ST-C, but it had a similar cellulose conversion rate as ST-C. In order to discover the reason for this disparity, the specific surface area (SSA), another factor reported to affect the enzymatic hydrolysis of cellulose, was investigated. The SSA of ET-C was slightly higher at $0.08 \mathrm{~m}^{2} / \mathrm{g}$ compared to $0.06 \mathrm{~m}^{2} / \mathrm{g}$ that of the ST-C sample. The small difference in the SSA of ST-C and ET-C seemed insignificant when compared to $8.47 \mathrm{~m}^{2} / \mathrm{g}$, the value of the IT-C sample. In a previous work, the surface areas of Avicel-based cellulose I and cellulose III were 0.64 and $0.61 \mathrm{~m}^{2} / \mathrm{g}$, respectively [12]. After IL pretreatment, the surface area of corn stover increased from 0.7 to $15.1 \mathrm{~m}^{2} / \mathrm{g}$ [33]. Therefore, the SSA obviously was not a major factor affecting the hydrolysis of ET-C and ST-C. From the viewpoint of enzyme accessibility, a larger surface area exposure could enhance the cellulose digestibility. Nevertheless, except for IT-C, the other pretreatments had only limited impact on the surface area of the samples. 
Table 2 The lattice spacing (d-spacing) of cellulose samples

\begin{tabular}{llll}
\hline Sample & \multicolumn{2}{l}{ d-Spacing (A) } \\
\cline { 2 - 4 } & (110) & $\mathbf{( 1 1 0 )}$ & $\mathbf{( 0 2 0 )}$ \\
\hline UN-C (Cellulose I $\left.I_{\alpha}\right)$ & 5.45 & 5.45 & 3.98 \\
GT-C (Cellulose I $\left.{ }_{\beta}\right)$ & 5.48 & 5.48 & 3.95 \\
IT-C (Cellulose II) & 5.91 & 4.11 & 4.11 \\
ST-C (Cellulose II) & 7.11 & 4.40 & 4.13 \\
ET-C (Cellulose III) & 7.37 & 4.26 & 4.26 \\
\hline
\end{tabular}

All three pretreatment reagents, $\mathrm{NaOH}, \mathrm{EDA}$, and [BMIM]Cl, could form hydrogen bonds with cellulose, and the stability order of the hydrogen bonds between pretreatment reagent and cellulose was $[\mathrm{BMIM}] \mathrm{Cl}>$ EDA $>\mathrm{NaOH}$. From the results of cellulose crystallinity and surface area in this study, we demonstrated that the crystalline cellulose structure was stable, and only a strong competitive hydrogen donor-acceptor, such as ionic liquid, could destroy the stable structure and increase the enzyme accessibility of native cellulose. These results could also explain why dilute acid pretreatment, a leading pretreatment technology for lignocellulose feedstock, was unable to loosen the compact structure of cellulose, because dilute sulfuric acid could not form hydrogen bonds with cellulose. This may be the reason that dilute acid pretreatment was not as effective as alkali pretreatment, especially ammonia technology for high crystallinity lignocellulosic feedstock [34-36].

In addition, wettability was reported to be able to predict the enzymatic hydrolysis of cellulose [10]. A higher water contact angle value of the samples indicated more hydrophobicity and inferior wettability. The correlation of wettability and cellulose conversion rate of various allomorphs is shown in Figure 5b. There was a negative correlation between the water contact angle and the cellulose conversion rate except for EC-T. The water absorption value is an indirect measure for internal pore volume and crystallinity of cellulose samples. The increase of cellulose wettability also enabled free enzymes to diffuse more easily from the solution to the cellulose surface [20].
All the characterization results revealed that the EC-T sample had special properties. Although its crystallinity and water contact angle were higher than these of ST-C, its enzymatic hydrolysis efficiency was similar to that of ST-C, which might contribute to the crystal allomorph. Comparing the crystal parameters of various allomorphs shown in Table 2, the distance of lattice 1Ī0 plane of cellulose III was longer than that of cellulose II, and significantly longer than that of cellulose I. The results revealed that the intermolecular force between cellulose chains was weaker with increasing distance. In addition, the enhanced enzymatic digestibility of cellulose III was reported to be related to the "amorphous-like" nature of its surface chains [12].

According to the integrated experimental results (Table 3), the most digestible enzymatic hydrolysis allomorph was amorphous cellulose, followed by cellulose III, cellulose II, cellulose $\mathrm{I}_{\alpha}$, and cellulose $\mathrm{I}_{\beta}$. When the cellulose crystallinity index was similar, the allomorph type was the dominant factor. Amorphous content had a strong positive influence on cellulose digestibility. Water contact angle was also an important factor in the evaluation of the enzymatic hydrolysis efficiency of cellulose, except in the case of cellulose III.

\section{Conclusion}

In this paper, four types of cellulose allomorphs were prepared. Ionic liquid pretreatment significantly altered the ultrastructure and morphology of cellulose samples, making cellulose much easier for enzymes to digest due to its significantly high amorphous content. However, when the impact of amorphous content was not considered, the allomorph easiest for enzymes to digest was cellulose III, followed by cellulose II, cellulose $\mathrm{I}_{\alpha}$, and cellulose $\mathrm{I}_{\beta}$. When the cellulose crystallinity index was similar, the allomorph type was the dominant factor. Amorphous content had a strong positive influence on cellulose digestibility. Water contact angle was also an important factor for evaluating the enzymatic hydrolysis efficiency of cellulose except for cellulose III. High wettability of cellulose enhanced the enzymatic hydrolysis when the crystal allomorph of cellulosic samples was the same.

Table 3 Cellulose structure and enzymatic digestibility

\begin{tabular}{|c|c|c|c|c|c|}
\hline Pretreatment & Allomorph & Crl (\%) & Water contact angle ${ }^{\mathrm{a}}\left({ }^{\circ}\right)$ & Surface area $\left(\mathrm{m}^{2} / \mathrm{g}\right)$ & Cellulose conversion $^{\mathrm{b}}(\%)$ \\
\hline$[\mathrm{BMIM}] \mathrm{Cl}$ & $\|$ & 20 & $29.5 \pm 0.6$ & 8.47 & $99 \pm 4$ \\
\hline EDA & III & 55 & $58.4 \pm 0.9$ & 0.08 & $74 \pm 2$ \\
\hline $\mathrm{NaOH}$ & $\|$ & 46 & $47.9 \pm 0.4$ & 0.06 & $76 \pm 3$ \\
\hline No treatment & $l_{a}$ & 61 & $60.7 \pm 0.8$ & - & $62 \pm 2$ \\
\hline Glycerol & $I_{\beta}$ & 69 & $66.0 \pm 0.7$ & - & $43 \pm 2$ \\
\hline
\end{tabular}

${ }^{\mathrm{a}}$ The reproducibility of cellulose water contact angle was conducted in triplicate.

${ }^{\mathrm{b}}$ The reproducibility of cellulose conversion was conducted in triplicate. 


\section{Abbreviations}

BET: Brunauer-Emmett-Teller; [BMIM]Cl: 1-butyl-3-methylimidazolium chloride; Crl: crystallinity index; EDA: ethylenediamine; ET-C: ethylenediamine treated cellulose; FTIR: Fourier transform infrared spectroscopy; GT-C: glycerol treated cellulose; HPLC: high performance liquid chromatography; L: ionic liquid; IR: infrared spectroscopy; IT-C: ionic liquid treated cellulose; SEM: scanning electron microscopy; SSA: specific surface area; ST-C: sodium hydroxide treated cellulose; UN-C: untreated cellulose; XRD: X-ray diffraction.

\section{Competing interests}

The authors declare that they have no competing interests.

\section{Authors' contributions}

TC prepared the materials, conducted the experiments, and wrote the manuscript. $J L$ and SL designed the experiments. MY and ZY conducted the compositional analyses. All authors read and approved the final manuscript.

\section{Acknowledgements}

The authors wish to thank Sandra Chang for her help in revising the paper. The authors also wish to thank Novozymes (China) Investment Co. Ltd. for their help in providing cellulase. This research was supported by the Ministry of Science and Technology of China (International S\&T cooperation projects, Grant No. 2013DFA60470, 2012DFG61700), the National High Technology Research and Development Program of China (Grant No. 2012AA101805), and the Public Science and Technology Research Funds Projects of Ocean (Grant No. 201005031)

Received: 9 April 2014 Accepted: 1 September 2014

Published online: 24 September 2014

\section{References}

1. PE Rez S, Mazeau K: Conformations, structures, and morphologies of celluloses. In Polysaccharides: Structural Diversity and Functional Versatility. 2nd edition. Edited by Dumitriu S. New York: Marcel Dekker; 2005:41-68.

2. Himmel ME, Ding SY, Johnson DK, Adney WS, Nimlos MR, Brady JW, Foust TD: Biomass recalcitrance: engineering plants and enzymes for biofuels production. Science 2007, 315(5813):804-807.

3. Salehi SMA, Karimi K, Behzad T, Poornejad N: Efficient conversion of rice straw to bioethanol using sodium carbonate pretreatment. Energ Fuel 2012, 26(12):7354-7361.

4. Lou H, Zhu JY, Lan TQ, Lai H, Qiu X: pH-Induced lignin surface modification to reduce nonspecific cellulase binding and enhance enzymatic saccharification of lignocelluloses. ChemSusChem 2013, 6(5):919-927.

5. Kim SB, Lee SJ, Lee JH, Jung YR, Thapa LP, Kim JS, Um Y, Park C, Kim SW: Pretreatment of rice straw with combined process using dilute sulfuric acid and aqueous ammonia. Biotechnol Biofuels 2013, 6(1):109.

6. Xu N, Zhang W, Ren S, Liu F, Zhao C, Liao H, Xu Z, Huang J, Li Q, Tu Y, Yu B, Wang Y, Jiang J, Qin J, Peng L: Hemicelluloses negatively affect lignocellulose crystallinity for high biomass digestibility under $\mathrm{NaOH}$ and $\mathrm{H}_{2} \mathrm{SO}_{4}$ pretreatments in Miscanthus. Biotechnol Biofuels 2012, 5(1):58.

7. Percival Zhang YH, Himmel ME, Mielenz JR: Outlook for cellulase improvement: Screening and selection strategies. Biotechnol Adv 2006, 24(5):452-481

8. Oh SY, Yoo Dl, Shin Y, Kim HC, Kim HY, Chung YS, Park WH, Youk JH: Crystalline structure analysis of cellulose treated with sodium hydroxide and carbon dioxide by means of X-ray diffraction and FTIR spectroscopy. Carbohyd Res 2005, 340(15):2376-2391.

9. Fan J, De Bruyn M, Budarin VL, Gronnow MJ, Shuttleworth PS, Breeden S, Macquarrie DJ, Clark JH: Direct microwave-assisted hydrothermal depolymerization of cellulose. J Am Chem Soc 2013, 135(32):11728-11731.

10. Stauner T, Silva IB, El Seoud OA, Frollini E, Petri DFS: Cellulose loading and water sorption value as important parameters for the enzymatic hydrolysis of cellulose. Cellulose 2013, 20(3):1109-1119.

11. Hall M, Bansal P, Lee JH, Realff MJ, Bommarius AS: Cellulose crystallinity a key predictor of the enzymatic hydrolysis rate. FEBS J 2010, 277(6):1571-1582

12. Chundawat SPS, Bellesia G, Uppugundla N, Da Costa SL, Gao D, Cheh AM, Agarwal UP, Bianchetti CM, Phillips GN, Langan P, Balan V, Gnanakaran S, Dale BE: Restructuring the crystalline cellulose hydrogen bond network enhances its depolymerization rate. J Am Chem Soc 2011, 133(29):11163-11174.

13. Igarashi K, Wada M, Samejima M: Activation of crystalline cellulose to cellulose III, results in efficient hydrolysis by cellobiohydrolase. FEBS J 2007, 274(7):1785-1792.

14. Cho HM, Gross AS, Chu J: Dissecting force interactions in cellulose deconstruction reveals the required solvent versatility for overcoming biomass recalcitrance. J Am Chem Soc 2011, 133(35):14033-14041.

15. Mittal A, Katahira R, Himmel ME, Johnson DK: Effects of alkaline or liquid-ammonia treatment on crystalline cellulose: changes in crystalline structure and effects on enzymatic digestibility. Biotechnol Biofuels 2011, 4:41.

16. Samayam IP, Hanson BL, Langan P, Schall CA: lonic-liquid induced changes in cellulose structure associated with enhanced biomass hydrolysis. Biomacromolecules 2011, 12(8):3091-3098.

17. Ciolacu D, Gorgieva S, Tampu D, Kokol V: Enzymatic hydrolysis of different allomorphic forms of microcrystalline cellulose. Cellulose 2011, 18(6):1527-1541.

18. Nishiyama $Y$, Langan $\mathrm{P}$, Chanzy $\mathrm{H}$ : Crystal structure and hydrogenbonding system in cellulose $\mathrm{I}_{\beta}$ from synchrotron $\mathrm{x}$-ray and neutron fiber diffraction. J Am Chem Soc 2002, 124(31):9074-9082.

19. Wada M, Heux L, Sugiyama J: Polymorphism of cellulose i family: reinvestigation of cellulose IV. Biomacromolecules 2004, 5(4):1385-1391.

20. Zhang J, Wang Y, Zhang L, Zhang R, Liu G, Cheng G: Understanding changes in cellulose crystalline structure of lignocellulosic biomass during ionic liquid pretreatment by XRD. Bioresour Techno/ 2014 151:402-405.

21. Zhang J, Zhang B, Zhang J, Lin L, Liu S, Ouyang P: Effect of phosphoric acid pretreatment on enzymatic hydrolysis of microcrystalline cellulose. Biotechnol Adv 2010, 28(5):613-619.

22. Li J, Li S, Fan C, Yan Z: The mechanism of poly(ethylene glycol) 4000 effect on enzymatic hydrolysis of lignocellulose. Colloids Surf $B$ : Biointerfaces 2012, 89:203-210.

23. Kataoka Y, Kondo T: FT-IR microscopic analysis of changing cellulose crystalline structure during wood cell wall formation. Macromolecules 1998, 31(3):760-764.

24. Gao D, Chundawat SPS, Sethi A, Balan V, Gnanakaran S, Dale BE: Increased enzyme binding to substrate is not necessary for more efficient cellulose hydrolysis. Proc Natl Acad Sci 2013, 110(27):10922-10927.

25. Russell JB, Muck RE, Weimer PJ: Quantitative analysis of cellulose degradation and growth of cellulolytic bacteria in the rumen. FEMS Microbiol Ecol 2009, 67(2):183-197.

26. Mansfield S, Meder R: Cellulose hydrolysis - the role of monocomponent cellulases in crystalline cellulose degradation. Cellulose 2003, 10(2):159-169.

27. Park S, Baker JO, Himmel ME, Parilla PA, Johnson DK: Cellulose crystallinity index: measurement techniques and their impact on interpreting cellulase performance. Biotechnol Biofuels 2010, 3:10

28. Wada M, Kwon GJ, Nishiyama Y: Structure and thermal behavior of a cellulose i -ethylenediamine complex. Biomacromolecules 2008, 9(10):2898-2904.

29. Cheng G, Varanasi P, Li C, Liu H, Melnichenko YB, Simmons BA, Kent MS, Singh S: Transition of cellulose crystalline structure and surface morphology of biomass as a function of ionic liquid pretreatment and its relation to enzymatic hydrolysis. Biomacromolecules 2011 12(4):933-941.

30. Wada M, Heux L, Nishiyama $Y$, Langan P: The structure of the complex of cellulose I with ethylenediamine by X-ray crystallography and crosspolarization/magic angle spinning ${ }^{13} \mathrm{C}$ nuclear magnetic resonance. Cellulose 2009, 16(6):943-957.

31. Igarashi K, Uchihashi T, Koivula A, Wada M, Kimura S, Okamoto T, Penttila M, Ando T, Samejima M: Traffic jams reduce hydrolytic efficiency of cellulase on cellulose surface. Science 2011, 333(6047):1279-1282.

32. Bertran MS, Dale BE: Determination of cellulose accessibility by differential scanning calorimetry. J Appl Polym Sci 1986, 32(3):4241-4253.

33. Li C, Cheng G, Balan V, Kent MS, Ong M, Chundawat SPS, Sousa LD, Melnichenko YB, Dale BE, Simmons BA, Singh S: Influence of physico-chemical changes on enzymatic digestibility of ionic liquid and AFEX pretreated corn stover. Bioresource Technol 2011, 102(13):6928-6936.

34. Silverstein RA, Chen Y, Sharma-Shivappa RR, Boyette MD, Osborne J: A comparison of chemical pretreatment methods for improving 
saccharification of cotton stalks. Bioresource Technol 2007,

98(16):3000-3011.

35. Chen M, Zhao J, Xia L: Comparison of four different chemical pretreatments of corn stover for enhancing enzymatic digestibility. Biomass Bioenergy 2009, 33(10):1381-1385.

36. Li C, Knierim B, Manisseri C, Arora R, Scheller HV, Auer M, Vogel KP, Simmons BA, Singh S: Comparison of dilute acid and ionic liquid pretreatment of switchgrass: Biomass recalcitrance, delignification and enzymatic saccharification. Bioresource Technol 2010, 101(13):4900-4906.

doi:10.1186/s13068-014-0134-6

Cite this article as: Cui et al:: The correlation between the enzymatic

saccharification and the multidimensional structure of cellulose changed by

different pretreatments. Biotechnology for Biofuels 2014 7:134.

\section{Submit your next manuscript to BioMed Central and take full advantage of:}

- Convenient online submission

- Thorough peer review

- No space constraints or color figure charges

- Immediate publication on acceptance

- Inclusion in PubMed, CAS, Scopus and Google Scholar

- Research which is freely available for redistribution 